\title{
Spatial Analysis of Groundwater Quality Using Geographic Information System - A Case Study
}

\author{
S. Krishnaraj ${ }^{1}$, Sanjiv Kumar ${ }^{2}$ and K.P. Elango ${ }^{3}$ \\ ${ }^{I}$ Department of Petrochemical Engg., R.V.S College of Engineering \& Technology, Coimbatore, India \\ ${ }^{2}$ School of Sciences, IGNOU, New Delhi, India. \\ ${ }^{3}$ Department of Chemistry, Gandhigram Rural Institute-Deemed University, Gandhigram, India.
}

\begin{abstract}
Groundwater serves as the main sources of water in the urban environment, which is used for drinking, industrial and domestic purposes and often, it is over exploited. Now a days, the groundwater is facing threats due to anthropogenic activities. In this study, groundwater samples were collected in four different seasons from 100 predetermined bore wells and open wells representing four blocks of Karur district. The water samples were analyzed for physico-chemical parameters like TDS, TH, TA Chloride, Fluoride and WQI using standard techniques in the laboratory. Also, geographic information system-based groundwater quality mapping in the form of visually communicating contour maps was developed using ArcGIS-version 9.0 software to delineate spatial distribution in physicochemical characteristics of groundwater samples. The final integrated map shows three priority classes such as Excellent, Good and Poor groundwater quality zones of the study area and provides a guideline for the suitability of groundwater for domestic purposes
\end{abstract}

Keywords: GIS, Groundwater, Spatial variation, groundwater quality.

\section{Introduction}

In India, most of the population is dependent on groundwater as the only source of drinking water supply [1,2, and 3]. The groundwater is believed to be comparatively much clean and free from pollution than surface water. Groundwater can become contaminated either naturally or because of numerous types of human activities, residential, municipal, commercial, industrial, and agricultural activities can all affect groundwater quality $[4,5,6,7,8,9$, and 10$]$.

GIS is an effective tool for groundwater quality mapping and essential for monitoring the environmental change detection. GIS has been used in the map classification of groundwater quality, based on correlating total dissolved solids (TDS) values with some aquifer characteristics or land use and land cover[11]. Other studies have used GIS as a database system in order to prepare maps of water quality according to concentration values of different chemical constituents. In such studies, GIS is utilized to locate groundwater quality zones suitable for different usages such as irrigation and domestic [12]. Babiker et al.[13] proposed a GIS-based groundwater quality index method which synthesizes different available water quality data by indexing them numerically relative to the WHO standards. The use of GIS technology has greatly simplified the assessment of natural resources and environmental concerns, including groundwater.

In groundwater studies, GIS is commonly used for site suitability analysis, managing site inventory data, estimation of groundwater vulnerability to contamination, groundwater flow modeling, modeling solute transport and leaching, and integrating groundwater quality assessment models with spatial data to create spatial decision support systems [14]. A GIS-based study was carried out by Barber et al. [15] to determine the impact of urbanization on groundwater quality in relation to land-use changes. Nas and Berktay [16] have mapped urban groundwater quality in Koyna, Turkey, using GIS. For any city, a ground water quality map is important to evaluate the water safeness for drinking and irrigation purposes and also as a precautionary indication of potential environmental health problems.

Singh and Lawrence [17] prepared a groundwater quality map in GIS successfully for Chennai city, Tamilnadu, India but a groundwater quality assessment in Dhanbad district, Jharkhand, India was much more difficult due to the spatial variability of multiple contaminants and wide range of indicators that could be measured. The present study attempts to map the spatial distribution of groundwater quality parameters for Karur District using GIS.

\subsection{Study area:}

\section{Materials and Methods}

The Karur district of Tamil Nadu, India is located at $10.95^{\circ} \mathrm{N}$ and $78.08^{\circ} \mathrm{E}$ with a mean elevation 122 $\mathrm{m}$. The average annual rainfall is about $855 \mathrm{~mm}$. The city gets most of its seasonal rainfall from the north east monsoon between late September to mid November. Vast mineral deposits, availability of water and good infrastructure are conducive for industrialization in the Amravati river basin of Karur has resulted in heavy 
Textile based industrialization. Many small, medium and large scale textile industries are situated in the region and these establishments have adversely affected the ground water quality. Besides, the increased population and improper drainage system in the study area have immense potential to influence the ground water quality

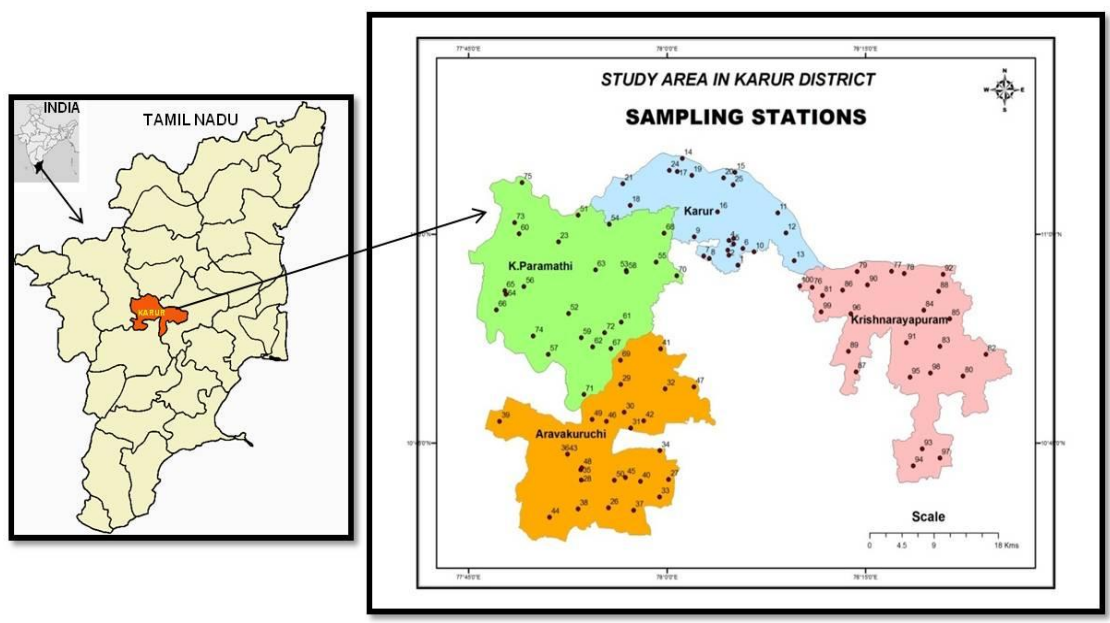

Figure 1. Map showing the study area with sampling stations.

2.2. Sample collection: A total of 100 water quality monitoring stations were identified (Fig.1) and water samples were collected in the middle month of four seasons namely post-monsoon (January - March), summer (April -June), pre-monsoon (July - September) and monsoon (October - December) of the year 2012.

2.3. Parameters under monitoring: The groundwater samples were analyzed for parameters which include $\mathrm{pH}$, EC, TDS, TA, TH, Ca (II), Mg (II), Na, K, fluorides, sulphates and chlorides using standard protocols and the quality of the data was ensured through careful standardization.

\subsection{Water Quality Index (WQI)}

The water quality index (WQI) of groundwater was calculated using weighted Arithmetic Index method and quality rating / sub index (Qi) corresponding to the $\mathrm{i}^{\text {th }}$ parameter $\mathrm{P}_{\mathrm{i}}$ is a number reflecting the relative value of this parameter.

Step I: Unit weight (Wi) was calculated by a value inversely proportional to the recommended standard $\left(\mathrm{S}_{\mathrm{i}}\right)$ of the corresponding parameter.

Step II: Quality rating (Qi) is calculated by using the following expression

$$
\text { Qi }=\sum_{i=1}^{n}[(M i-I i) /(S i-I i)] * 100
$$

Where $\mathrm{Mi}=$ Estimated values of the $\mathrm{i}^{\mathrm{th}}$ parameter in the Lab

$\mathrm{I} i=$ Ideal values of the $i^{\text {th }}$ parameter

$\mathrm{Si}=$ Standard values of the $\mathrm{i}^{\text {th }}$ parameter

All the Ideal values (Ii) are taken as zero except for $\mathrm{pH}=7$ and $\mathrm{F}=1.0$

Step III: The overall WQI was calculated by aggregating the quality rating (Qi) with unit weight (Wi) linearly $\mathrm{WQI}=\left(\sum_{i=1}^{n} Q i W_{i}\right) /\left(\sum_{i=1}^{n} W_{i}\right)$

TDS, pH, chlorides, fluorides, total hardness, total alkalinity, calcium and magnesium were recognized as preliminary indication of quality and it is used in calculating WQI for public water supply.

Table 1. Water Quality Guidelines BIS Standards - 10500

\begin{tabular}{|c|c|c|c|}
\hline S.No & Parameters & Acceptable (ppm) & Max. Allowable (ppm) \\
\hline 1 & Total Dissolved solids & 500 & 2000 \\
\hline 2 & Total Alkalinity ( as $\mathrm{CaCO}_{3}$ ) & 200 & 600 \\
\hline 3 & Total Hardness ( as $\mathrm{CaCO}_{3}$ ) & 300 & 600 \\
\hline 4 & Chloride ( as $\mathrm{Cl}$ ) & 250 & 1000 \\
\hline 5 & Fluoride ( as F ) & 1.0 & 1.5 \\
\hline 6 & Sulphate (as $\left.\mathrm{SO}_{4}\right)$ & 200 & 400 \\
\hline 7 & Calcium( as $\mathrm{Ca}$ ) & 75 & 200 \\
\hline 8 & Magnesium ( as Mg) & 30 & 100 \\
\hline
\end{tabular}


Table 2. Water quality classification based on WQI value

\begin{tabular}{|c|c|c|}
\hline S.No & WQI value & Water Quality \\
\hline 1 & $0-24$ & Excellent \\
\hline 2 & $25-50$ & Good \\
\hline 3 & $50-74$ & Poor \\
\hline 4 & $75-100$ & Very Poor \\
\hline 5 & Above 100 & Unfit for drinking \\
\hline
\end{tabular}

\subsection{Total Dissolved Solids (TDS)}

\section{Results and Discussion}

The mineral constituents dissolved in water constitute dissolved solids. The total concentration of dissolved minerals in water is a general indication of the overall suitability of water for many types of uses. The Total Dissolved Solids (TDS) was classified in to four ranges $(0-500 \mathrm{mg} / \mathrm{l}, 501-1000 \mathrm{mg} / \mathrm{l}, 1001-2000 \mathrm{mg} / \mathrm{l}$ and $>2000 \mathrm{mg} / \mathrm{l})$. The spatial variation map for TDS was prepared based on these ranges and presented in Fig. 2.

From the spatial variation map it was observed that the very high range of TDS value (>2000 mg/l) was distributed in the western part of the Karur district (K.Paramathi block) and it covered about $11 \%$ of total area. The high range of TDS value $(1001-2000 \mathrm{mg} / \mathrm{l})$ was found to be widely distributed throughout the district, it covered about 53\% of the total study area. Medium range of TDS value (501-1000 mg/l) was scattered throughout the district covering about $31 \%$ of the study area and the permissible limit of TDS $(<500 \mathrm{mg} / \mathrm{l}) \mathrm{was}$ observed only in Karur block (about $5 \%$ of the study area). Groundwater with less than $500 \mathrm{mg} / \mathrm{l}$ of dissolved solids is generally satisfactory for domestic use and for many industrial purposes. If the Water with more than $1000 \mathrm{mg} / \mathrm{L}$ of dissolved solids usually gives disagreeable taste or makes the water unsuitable in other respects.

\subsection{Total Alkalinity}

The standard desirable limit of alkalinity of potable water is $200 \mathrm{mg} / \mathrm{l}$. The maximum Permissible level is $600 \mathrm{mg} / \mathrm{l}$. Fig. 3 shows spatial distribution of Total Alkalinity in the groundwater of the study area, varied from 80 to $948 \mathrm{mg} / \mathrm{l}$. High alkaline water $>600 \mathrm{mg} / \mathrm{l}$ was observed only in eastern part of the Karur block . Excessive alkalinity may cause eye irritation in human and chlorosis in plants. Low concentration of alkalinity $(<200 \mathrm{mg} / \mathrm{l})$ was observed in very small area of the northern and southern part of the Karur block. About $92 \%$ area of the study area of the Karur district was observed to have the Alkalinity of the range $200-600 \mathrm{mg} / \mathrm{l}$.

\subsection{Hardness}

Hardness in water is caused primarily by the presence of carbonates and bicarbonates of calcium and magnesium, as well as due to sulphates, chlorides and nitrates. The Total hardness was classified in to three ranges $(<300 \mathrm{mg} / \mathrm{l}, 300-600 \mathrm{mg} / \mathrm{l}$ and $>600 \mathrm{mg} / \mathrm{l})$ and based on these ranges the spatial variation map for total hardness was prepared and presented in Fig. 4. From the map it was observed that the low range of total hardness $<300 \mathrm{mg} / \mathrm{l}$ (permissible limit) present in the Aravakurichi block groundwater and medium range 300 $600 \mathrm{mg} / \mathrm{l}$ (acceptable limit) was observed in major part of K.Paramathi and Karur blocks. The high range of total hardness (>600 mg/l) was observed only in Karur block.

\subsection{Chloride}

Chloride is one of the most important parameter in assessing the water quality and higher concentration of chloride indicates higher degree of organic pollution. According to BIS/ICMR the permissible limit of chloride in drinking water is $250 \mathrm{mg} / \mathrm{l}$. Fig. 5, Spatial distribution of Chloride in the study area, was obtained due to the chloride concentration fluctuating between 48 and $575 \mathrm{mg} / \mathrm{l}$. High concentration of chloride $>250$ $\mathrm{mg} / \mathrm{l}$ was observed in the entire area of Krishnarayapuram block, major part of the K.Paramathi block and small area respectively in Karur and Aravakurichi blocks.. This may be due to natural processes such as the passage of water through natural salt formations in the earth or it may be an indication of pollution from industrial or domestic use [21]. In drinking water, high chloride content may lead to laxative effects [22,23]. Low concentration of chloride $<250 \mathrm{mg} / \mathrm{l}$ was found in major area of the Aravakurichi block.

\subsection{Fluoride:}

Groundwater usually contains fluoride dissolved by geological formation. The desirable limit of Fluorides is $0.5-1.5 \mathrm{mg} / \mathrm{l}$, beyond this limit the water is considered as poor quality. Based on these range the spatial variation map for Fluorides was prepared and presented in Fig. 6. From the figure it was evident that major parts of the district have good range $0.5-1.0 \mathrm{mg} / \mathrm{l}$ of Fluorides. A smaller portion of Southern part of the study area have poor range $>1.5 \mathrm{mg} / \mathrm{l}$ (exceeding the higher limit) of fluoride contents and also a small part have moderate quality range (1.0-1.5 mg/l). 


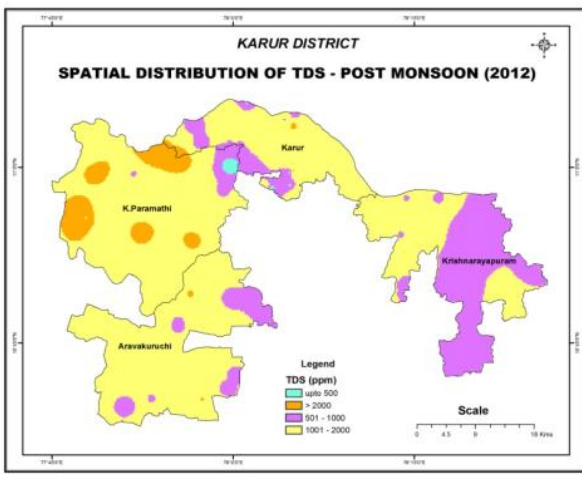

Figure 2. Spatial Distribution of TDS

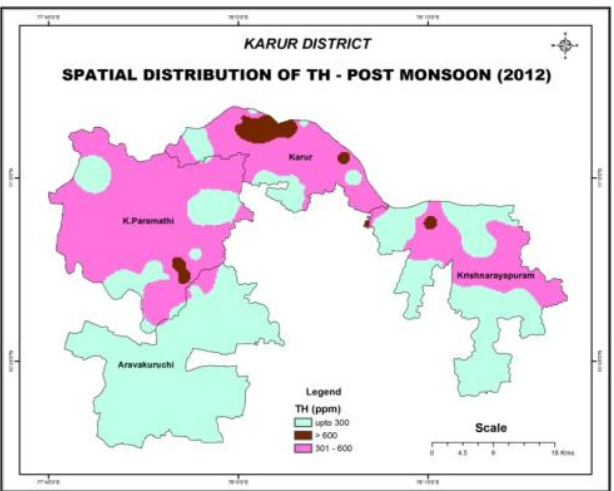

Figure 4. Spatial Distribution of TH

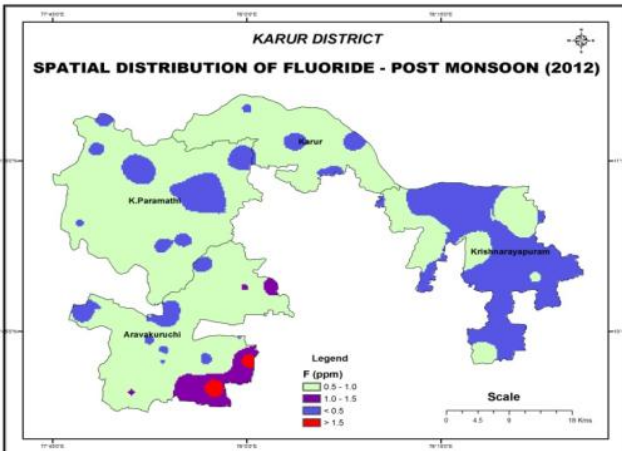

Figure 6. Spatial Distribution of Fluoride

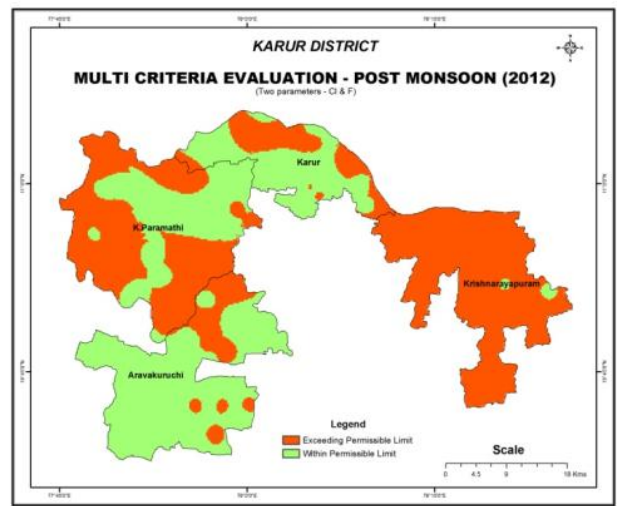

Figure 8. Spatial distribution of $\mathrm{Cl} \& \mathrm{~F}$

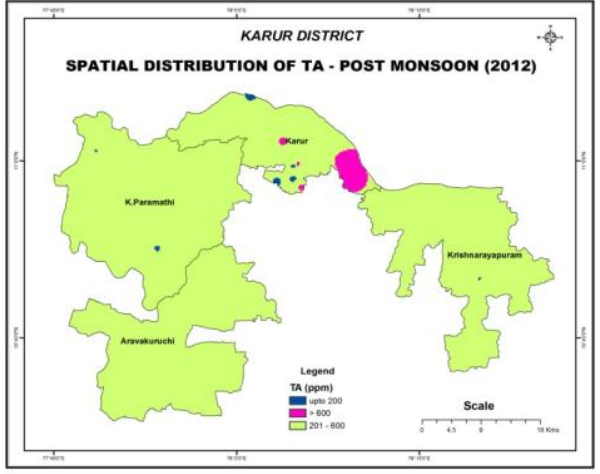

Figure 3. Spatial Distribution of TA

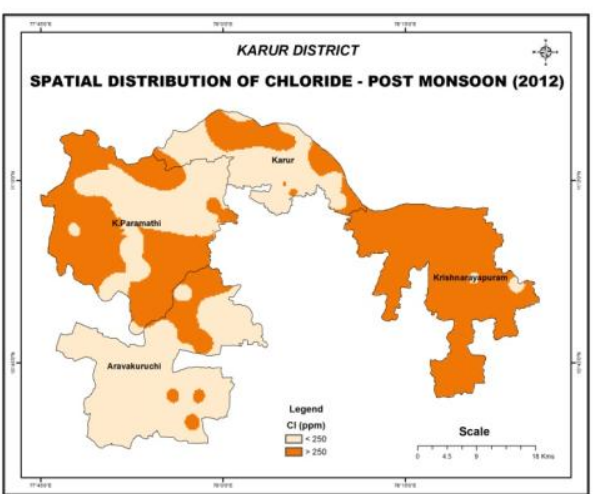

Figure 5. Spatial Distribution of Chloride

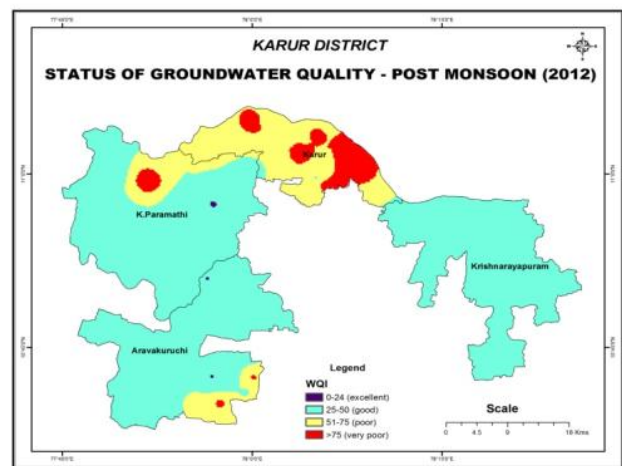

Figure 7. Status of Groundwater quality

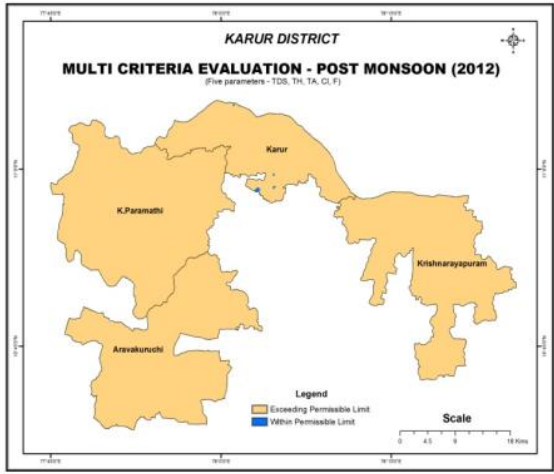

Figure 9. Multi-criteria evaluation 


\subsection{Water Quality Index (WQI):}

Fig. 7 shows Spatial Distribution of WQI in the study area and it was varying from 29 to107. Major part of Aravakurichi block as well as K.Paramathi block and the entire Krishnarayapuram block were found to have good water (WQI in the range of 25-50). About 17 percent of total study area was found to have poor quality of groundwater only. From the map it was cleared that the entire Karur block was distributed with poor and very poor quality of groundwater only. The south-east corner area of the Aravakurichi block too was found to have poor quality of groundwater only.

\subsection{Multi Criteria Evaluation}

The multi criteria evaluation map for two parameters (chloride \& fluoride) is represented by Fig 8 . The map clearly explains the spatial distribution of concentration of Chloride and fluoride exceeding the permissible limit. The complete Krishnarayapurm block, part of the Karur block, major part of the K.Paramathi block and small part of Aravakurichi block groundwater were found to have Chloride and Fluoride in exceeding their limit. The Fig. 9 represents the multi criteria Evaluation map for five parameters (TDS, TA, TH, and Cl \& F). The map confirms that except two or three monitoring stations in Karur block, all the groundwater samples were found to have these five parameters more than the permissible limit.

\section{Conclusion}

This study has demonstrated the utility of GIS combined with analytical data to assess and mapping of groundwater quality. The spatial distribution map of Total Dissolved Solids, Total Alkalinity, Total Hardness, Chloride and Fluoride shows that, these parameters were not within the permissible limit throughout the study area uniformly. The spatial distribution map of hardness concentration illustrates that 64 percent of the groundwater samples contain total hardness within the limit, 28 percent within the permissible limit and 8 percent exceeding the limit. The spatial distribution map of Alkalinity concentration illustrates that only 5 percent of groundwater samples are within the limit and 92 percent within permissible limit. About 11 percent of TDS concentration in groundwater samples of the study area exceeds the maximum permissible limit and 5 percent alone in the potable range. The interpreted water quality Index indicates that around 68 percent of the study area groundwater samples lie in range of good quality and 28 percent lies in range of poor quality. Only 69 percent of the study area was distributed with groundwater within the permissible limit of fluoride concentration. The spatial distribution map of Chloride concentration illustrates that only 44 percent of the groundwater samples contain Chlorides within the limit. Thus spatial distribution maps of various quality parameters are used to demarcate the locational distribution of water quality in a comprehensive manner and help in suggesting groundwater suitable for domestic purposes.

\section{References}

[1]. National Institute of Urban Affairs (NIUA) (2005). Status of Water Supply, Sanitation and Solid Waste Management in Urban Areas, New Delhi, URL: http://urbanindia.nic.in/moud/what'snew/main.htm.

[2]. A. Mahmood and A. Kundu A (2005). India's demography in 2050: size, structure and habitat. Discussion Paper, IWMI-TATA partners meet - 2005, Anand, Gujarat.

[3]. S.J.Phansalkar, V. Kher and P. Deshpande Expanding Rings of Dryness: Water Imports from Hinterlands to Cities and the Rising Demands of Mega-Cities, in IWMI-Tata Annual Partner's Meet, Anand, 2005.

[4]. U.S. EPA, A review of methods for assessing aquifer sensitivity and ground water Vulnerability to pesticide contamination. U.S. EPS. EPA/813/R-93/002 (2005).

[5]. M.Jalali , Nitrates leaching from agricultural land in Hamadan, western Iran. Agric. Ecosyst. Environ., 110: 2005, 210-218.

[6]. C.N.Rivers, K.M.Hiscock ,N.A. Feast ,M.H. Barrett and P.F.DennisF ; Use of nitrogen isotopes to identify nitrogen contamination of the Sherwood sandstone aquifer beneath the city of Nottingham, UK. Hydrogeol. J., 4(1): 1996, 90-102.

[7]. K.N.Kim , H.J.Rajmohan ,G.S. Kim , Hwang and M.J.Cho., Assessment of groundwater chemistry in a coastal region (Kunsan, Korea) having complex contaminant sources: A stoichiometric approach. Environ. Geol., 46(6-7): 2004, 763-774.

[8]. K.Srinivasamoorthy ,C. Nanthakumar, M.Vasanthavigar , K.Vijayarag havan ,R. Rajiv Gandhi, S.Chidambaram, P.Anandhan,R. Manivannan and S. Vasudevan ., Groundwater quality assessment from a hard rock terrain, Salem district of Tamilnadu, India, Arabian J. Geosci., 2009: 112-115

[9]. K.Goulding ., Nitrate leaching form arable and horticultural land. Soil Use Manage., 16: 2000, $145-151$.

[10]. J.Pacheco, S.Cabrera .,Groundwater contamination by nitrates in the Yucatan Peninsula, Mexico. Hydrogeol. J.,5(2): 1997, 47-53.

[11]. S.S.Asadi , P.Vuppala, M.A.Reddy. Remote sensing and GIS techniques for evaluation of groundwater quality in Municipal Corporation of Hyderabad (Zone-V), India. Int. J. Environ. Res. Public Health, 4(1): 2007, 45-52.

[12]. S.Yammani ., Groundwater quality suitable zones identification: application of GIS, Chittoor area, Andhra Pradesh, India. Environ. Geol., 53(1): 2007, 201-210.

[13]. I.S.BabikerS, A.M.Mohamed and T.Hiyama.,Assessing groundwater quality using GIS. Water Resour.Manage., 21(4): 2007, 699 715 .

[14]. B.A.Engel, K.C.S.Navulur .,The role of geographical information systems in groundwater Engineering. In: Delleur JW (ed) The handbook of groundwater engineering. CRC, Boca Raton, 1999pp. 703-718.

[15]. C.Barber, C.J.Otto, L.E.Bates and K.J.Taylor.,Evaluation of the relationship between land-use changes and groundwater quality in a water-supply catchment, using GIS technology: the Gwelup Wellfield, Western Australia. J. Hydrogeol., 4(1): 1996, 6-19.

[16]. B.Nas, A.Berktay., Groundwater quality mapping in urban groundwater using GIS. Environ. Monitor. Assess., 160(1-4): 2010, $215-227$. 
[17]. D.S.H.Singh, J.F.Lawrence, Groundwater quality assessment of shallow aquifer using geographical information system in part of Chennai city Tamilnadu. J. Geol. Soc. India, 69: 1067-1076(2007).

[18]. APHA, Standard methods for the examination of water and wastewater (American Public Health Association), Washington DC, 1985.

[19]. WHO, Guidelines of drinking water quality Recommendation: the 3rd edition. Geneva: World Health Organisation. 2 : 2006,

[20]. WHO (World Health Organization), Health hazards from nitrates in drinking water. WHO, Regional Office for Europe, 1985.

[21]. C.E.Renn, Investigating water problems, A water analysis manual, Chestertown.

[22]. S.Dahiya and A.Kaur, Assessment of physical and chemical characteristics of underground water in rural areas of Tosham subdivision, Bhiwani-Haryana, International Journal of Environment and pollution, 6(4), 1999, pp 281-288.

[23]. S.Raviprakash and G.K.Rao, The chemistry of ground water in Paravada area with regard to their suitability for domestic and irrigational purposes, Indian Journal of Geochemistry, 4, 1989, 39-54. 